\title{
Editorial for special issue on USTB-RWTH Aachen's 40 years of collaboration
}

\author{
Yan-ping Bao \\ State Key Laboratory of Advanced Metallurgy, University of Science and Technology Beijing, Beijing 100083, China
}

The year of 2019 is the 40th anniversary of the signing of the inter-school collaboration agreement between University of Science and Technology Beijing (USTB) and RWTH Aachen University. It is also the first friendly inter-school collaboration agreement signed between domestic universities and foreign universities after China's reform and openingup. In order to commemorate this important historical event, the special academic issue is published in International Journal of Minerals, Metallurgy and Materials after friendly negotiation between RWTH Aachen and USTB. The special papers adopted the way of special invitation, mainly inviting: (1) famous professors in mining, metallurgy, and materials fields of the two universities; (2) young scholars who have studied in the two universities through the collaboration agreement between the two universities.

RWTH Aachen University is one of the members of IDEA league, a famous European Union of science and engineering university, and also a member of German elite universities. It has obvious advantages in metallurgy, materials, machinery, and other disciplines. USTB is one of the first batch of universities selected for the "211 Project" in China, and also one of the universities selected for the construction of national advantageous disciplines. Its metallurgy and materials disciplines enjoy a high reputation in the world. As the contact person of collaboration between USTB and RWTH Aachen University, I am honored to be the special editor of this commemorative academic special issue.

This special issue includes 14 papers, including 12 scientific research papers and 2 review papers. All papers were mainly focused on the research development in RWTH and USTB, as well as the frontiers topics of the two universities.

First of all, the studies of advanced materials are also included. Li and Luo [1] focused on the medium-Mn steels, reviewing their hot forming process and the application, pointing out the future researches should be targeted on the commercialization of hot forming of medium-Mn steels. Wang et al. [2] reviewed the effect of microstructure on corrosion be- havior of ultra-high strength martensite steel, exploring the corrosion mechanisms of additive manufacturing ultra-high strength steels and the ideas for designing new ultra-high strength martensite steel. In RWTH, researches concerning the mechanical properties of high-manganese steels were cooperated with the Max Planck Institute for Iron Research. Bleck [3] from RWTH reported that the microstructures of high-manganese steels were characterized by the use of modern methods at the nm-scale. Besides, the high-manganese steels are affected by the strong interaction among the alloying elements as well as various crystal defects.

As the competitive research direction in USTB, a large amount of researchers devote to relevant topics concerning metallurgical process. $\mathrm{Xu}$ et al. [4] from USTB conducted a research about the effect of $\mathrm{Al}_{2} \mathrm{O}_{3}$ on the viscosity of $\mathrm{CaO}-$ $\mathrm{SiO}_{2}-\mathrm{Al}_{2} \mathrm{O}_{3}-\mathrm{MgO}-\mathrm{Cr}_{2} \mathrm{O}_{3}$ slags and reported that the viscosity of the slag increases gradually with the increase of the $\mathrm{Al}_{2} \mathrm{O}_{3}$ content within the range of $17 \mathrm{wt} \%$ to $29 \mathrm{wt} \%$. Xiao et al. [5] proposed a new method to produce high-quality bearing steel by using $\mathrm{Si} / \mathrm{Mn}$ deoxidization, which can significantly improve the fluidity of liquid steel and ensure satisfying fatigue life. Yu et al. [6] presented a novel approach of intercritical heat treatment for microstructure tailoring. Gu et al. [7] conducted a numerical study of stress distribution and fatigue behavior in terms of the effect of voids adjacent to inclusions with finite element modeling simulations under different assumptions. Besides of smelting process, safety issue is also a key point which should be paid extra attention during ironmaking and steelmaking. Jin and Niu [8] studied the possibility of exploding when different coals were applied in blast furnace injection.

On the other hand, researches in RWTH also produce valuable results, especially in the aspect of researches on the performance of advanced materials. Guo et al. [9] studied the influences of hydrogen on mechanical properties and fracture behaviour of $\mathrm{Fe}-22 \mathrm{Mn}-0.6 \mathrm{C}$ twinning induced plasticity steel. Ma et al. [10] simulated the austenite reversion in a 
medium-Mn alloy by the multiphase-field approach. The simulated microstructural morphology and phase transformation kinetics (indicated by the amount of phase) concurred well with experimental observations. Liu and Lian [11] discovered the stress-state dependence of the dynamic strain aging (DSA) effect on the deformation and fracture behavior of high-strength dual-phase steel at different deformation temperatures $\left(25\right.$ to $\left.400^{\circ} \mathrm{C}\right)$ and revealed the damage mechanisms under these various configurations, reporting that the stress state is contributing distinctly to the DSA effects in terms of both the magnitude of thermal hardening as well as the pattern of blue brittleness. Hytönen et al. [12] investigated the effect of the weld microstructure and inclusions on the brittle fracture initiation in a thermally aged ferritic highnickel weld of a reactor pressure vessel head. Zhang and Zaefferer [13] carried out a systematic study to understand the influence of sample preparation methods on the nanoindentation results of ductile metals.

Besides, there are also breakthrough concerning material preparation. Wang et al. [14] successfully fabricated the $(\mathrm{CoCrFeNi})_{95} \mathrm{Nb}_{5}$ high entropy alloy coatings on the substrate of Q235 steel by laser cladding technology, demonstrating fine controllability of high-performance high entropy alloy coating with laser cladding technology, offering guidance for laser cladding preparation of other $\mathrm{CoCrFeNi}-$ system HEA coatings.

Finally, I would like to give special thanks to Prof. Dieter Senk from RWTH, who offers great help as an official contact person between RWTH and USTB and his efforts during the paper invitation for this special issue. I also would like to give thanks to Prof. Jun-he Lian from Aalto University for his positive connections with authors for paper invitation and to Dr. Chao Gu from USTB for her valuable work on clerical issues. I also appreciate all authors for their papers and valuable works, as well as all reviewers for their helpful comments. We sincerely thank the Editorial Team of IJMMM for their hard work to get the publication of the special issue.

\section{References}

[1] S.S. Li and H.W. Luo, Medium-Mn steels for hot forming application in the automotive industry, Int. J. Miner. Metall. Mater., 28(2021), No. 5, p. 741.

[2] L. Wang, C.F. Dong, C. Man, Y.B. Hu, Q. Yu, and X.G. Li, Effect of microstructure on corrosion behavior of ultra-high strength martensite steel-A literature review, Int. J. Miner. Metall. Mater., 28(2021), No. 5, p. 754.

[3] W. Bleck, New insights into the properties of high manganese steel, Int. J. Miner. Metall. Mater., 28(2021), No. 5, p. 782.

[4] C.Y. Xu, C.W, R.Z. Xu, J.L. Zhang, and K.X. Jiao, Effect of $\mathrm{Al}_{2} \mathrm{O}_{3}$ on the viscosity of $\mathrm{CaO}-\mathrm{SiO}_{2}-\mathrm{Al}_{2} \mathrm{O}_{3}-\mathrm{MgO}-\mathrm{Cr}_{2} \mathrm{O}_{3}$ slags, Int. J. Miner. Metall. Mater., 28(2021), No. 5, p. 797.

[5] W. Xiao, Y.P. Bao, C. Gu, M. Wang, Y. Liu, Y.S. Huang, and G.T. Sun, Ultrahigh cycle fatigue fracture mechanism of highquality bearing steel obtained through different deoxidation methods, Int. J. Miner. Metall. Mater., 28(2021), No. 5, p. 804.

[6] Y.S. Yu, B. Hu, M.L. Gao, Z.J. Xie, X.Q. Rong, G. Han, H. Guo, and C.J. Shang, Determining role of heterogeneous microstructure in lowering yield ratio and enhancing impact toughness in high strength low alloy steel, Int. J. Miner. Metall. Mater., 28(2021), No. 5, p. 816.

[7] C. Gu, W.Q. Liu, J.H. Lian, and Y.P. Bao, In-depth analysis of the fatigue mechanism induced by inclusions for high-strength bearing steels, Int. J. Miner. Metall. Mater., 28(2021), No. 5, p. 826.

[8] L.Z. Jin and M.X. Niu, Micromorphology and safety properties of meager and meager-lean coal for blast furnace injection, Int. J. Miner. Metall. Mater., 28(2021), No. 5, p. 774.

[9] X.F. Guo, S. Zaefferer, F. Archie, and W. Bleck, Hydrogen effect on the mechanical behaviour and microstructural features of a $\mathrm{Fe}-\mathrm{Mn}-\mathrm{C}$ twinning induced plasticity steel, Int. J. Miner. Metall., 28(2021), No. 5, p. 835.

[10] Y. Ma, R. Zheng, Z.Y. Gao, U. Krupp, H.W. Luo, W.W. Song, and W. Bleck, Multiphase-field simulation of austenite reversion in medium-Mn steels, Int. J. Miner. Metall., 28(2021), No. 5, p. 847.

[11] W.Q. Liu and J.H. Lian, Stress state dependence of dynamic strain aging: Thermal hardening and blue brittleness, Int. J. Miner. Metall., 28(2021), No. 5, p. 854.

[12] N. Hytönen, Z.Q. Que, P. Arffman, J. Lydman, P. Nevasmaa, U. Ehrnstén, and P. Efsing, Effect of weld microstructure on brittle fracture initiation in the thermally aged boiling water reactor pressure vessel head weld metal, Int. J. Miner. Metall. Mater., 28(2021), No. 5, p. 867.

[13] J.-L. Zhang and Stefan Zaefferer, Influence of sample preparation on nanoindentation results of twinning-induced plasticity steel, Int. J. Miner. Metall., 28(2021), No. 5, p. 877.

[14] W.R. Wang, W. Qi, X.L. Zhang, X. Yang, L. Xie, D.Y. Li, and Y.H. Xiang, Superior corrosion resistance dependent laser energy density in $(\mathrm{CoCrFeNi})_{95} \mathrm{Nb}_{5}$ high entropy alloy coating fabricated by laser cladding, Int. J. Miner. Metall. Mater., 28(2021), No. 5, p. 888.

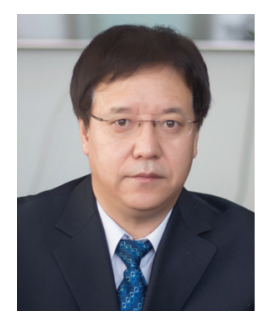

Yan-ping Bao is a professor at University of Science and Technology Beijing, China since 2001. He has published over 200 papers. His main research interests and contributions are steelmaking process optimization, alloy reduction applications, and steel cleanliness control. He is the first Chinese professor to win the "Willy Korf Excellent lecture Aaward" in 2012. 